\title{
THE SIGNIFICANCE OF A CHILD'S AGE AT THE TIME OF PARENTAL DIVORCE
}

\author{
Neil Kalter, Ph.D., and James Rembar, Ph.D.
}

The literature on children of divorce presents three theories on the relationship between a child's age at divorce and subsequent adaptation. Outpatient evaluations of 144 children of divorce, ranging in age from seven to 17 years, were coded for nature of emotional-hehavioral problems and overall degree of psychological adjustment. Divorce timing was unrelated to overall level of adjustment, but was associated significantly with different constellations of emotional-behavioral difficulties.

$\mathrm{W}$ ith the dramatic rise over the last 15 years in the rate of divorce in the United States, researchers have focused increasingly on the implications of parental divorce for the children involved. While the literature concerning children of divorce is still comparatively sparse, child clinicians and developmentally-oriented investigators have mounted a number of large-sample and longitudinal studies specifically aimed at understanding children's reactions and adjustments to divorce. Research with child psychiatric populations 9.13 .14 .17 .26 has been extended fruitfully to nonclinical groups of youngsters. ${ }^{7.8 .10 .22-24}$ At the same time, the richness of the clinical case study method has added to our knowl- edge of these youngsters. ${ }^{1.2 .18 .19}$ Together, these complementary strands of research have begun to yield valuable new data concerning the effects of parental divorce on child development.

Many of the research efforts cited, as well as the earlier pioneering work in this area, 2,11.12.15.21 make implicit and often explicit reference to the importance of the timing of the parental divorce in the child's life. Landis"1 stated that:

Divorce of parents affects children in various ways, depending on such factors as age of the child at the time of divorce.... (p. 7 )

Neubauer ${ }^{15}$ addressed this issue, saying that the

... significant variables in the Oedipal develop. ment of children with only one parent are timing of

Submitted to the Journal in Nolember 1979. Authors are at: Departments of Psychology and Psychatry. University of Michigun Medical Center. Ann Arbor (Kalter); and Department of Psychiatry, New. York Hospital-Cornell Medical Center. Westchester Division (Rembar, formerly at Department of Psychiatry, University of Michigan Medical Center). 
the loss, and the relationship of the child's sex to the sex of the missing parent. (p. 293)

\section{More recently, Gardner- noted that:}

There are some who believe that there are special ages at which children are particularly vulnerable to divorce. (p. 3)

In addition to pointed comments such as these, others, by their emphasis on a child's age in their research methods or conclusions, have clearly indicated that a youngster's developmental level as reflected by age at the time of divorce bears a relationship to the child's experience and subsequent emotional development. The purpose of this paper is to address the issue of the association between the timing of the parental divorce and its impact on the development of children. Relevant positions in the literature will be examined, followed by presentation of new data.

\section{LITERATURE REVIEW}

A review of the literature concerning the impact of divorce on children reveals three distinguishably different perspectives concerning the effects of the timing of the marital dissolution. These may be labeled, in rough developmental order, the cumulative effect hypothesis, the critical stage hypothesis, and the recency hypothesis. Proponents of the cumulative effect hypothesis maintain that the earlier the parental divorce occurs in the child's life, the more profound its impact will be. Gardner, ${ }^{4}$ referring to children of divorce, stated this view most succinctly:

Generally. I believe that the younger the child the more affected he or she will be by the loss of a parent. (p. 3)

Evidence in support of this statement has often appeared in the literature on the effects of father absence on child development. Hetherington, ${ }^{5.6}$ for example, found that father absence prior to age five is more disruptive for boys and girls than are later separations. Others ${ }^{20}$ have noted that divorce confronts very young children with the loss of a parent at a time when they lack the capacity to mourn effectively. This difficulty is regarded as potentially leading to serious long-term problems.

The critical stage hypothesis has also been supported in the literature, primarily by those with a psychoanalytic viewpoint. As Gardner ${ }^{4}$ stated:

Some psychologists and psychiatrists believe that between the ages of three and five-during the so-called Oedipal period-divorce can be particularly devastating. (p. 3)

Neubauer ${ }^{15}$ and McDermott ${ }^{12}$ are among those who have emphasized the importance of oedipal dynamics in youngsters whose parents are divorcing at about the time the child is between the ages of three and six. Westman ${ }^{25}$ has nicely summarized the psychodynamic view of expectable reactions of oedipal-aged youngsters, especially boys, to a parental separation. Briefly, those who hold the view that children will be especially vulnerable to the impact of divorce when it occurs during the child's oedipal years underscore the importance of oedipal fantasises and anxieties, magical thinking, guilt over an oedipal victory (if the child is the same sex as the departing parent), and the absence of an appropriate figure for important identifications (again, if the child is the same sex as the noncustodial parent). It is hypothesized, and there are reported clinical case studies that support the view, that parental divorce during the child's oedipal years is espe- 
cially traumatic and can have pronounced long-term as well as immediate effects.

The recency position is taken by those who see divorce as a trauma for children but one from which the youngster can recover relatively quickly (i.e., within a year or two). The majority of studies in which children of divorce are directly observed at the time the parents are separating demonstrates convincingly that nearly all children, regardless of their age, react to their parents' divorce with pain and distress. ${ }^{7,8}$ 10. 12. 22-24 But many of the children in these samples seemed to evidence progressively less distress with the passage of time. As Wallerstein and Kelly ${ }^{22}$ remarked, in reference to the adolescents in their sample,

... most of the young people whom we studied were able within a year following parental separation to take up their individual agendas and proceed toward adulthood at a more measured pace. (p. 503)

The findings of McDermott ${ }^{12}$ are consistent with this conclusion, but figures reported by Wallerstein and Kelly for the younger children in their sample, and by Hetherington, Cox and $\operatorname{Cox},{ }^{8}$ are more mixed.

Most investigators studying the effects of divorce on children appropriately enumerate and often discuss factors, other than the child's age or developmental level, that are important in determining reactions and adjustment to parental divorce. The child's predivorce developmental achievements and general adjustment, the extent of hostilities between the parents before and after divorce, visitation by the noncustodial parent, level of economic distress for the custodial parent and children, and changing family roles have all been elaborated . and illustrated. ${ }^{8.19}$.22, 25 Nonetheless, with respect to the timing of the divorce, the literature contains three decidedly differing points of view. It is our intent to provide a comparison of these perspectives in an effort to shed light on the possible differential effects of this important factor.

\section{METHOD}

\section{Sample}

The completed outpatient evaluations of children seen for psychiatric evaluation in the Department of Psychiatry at the University of Michigan during the period September 1976 to November 1977 were reviewed. There were 500 completed evaluations, averaging roughly 15 single-spaced typed pages. The evaluations were extensive; most consisted of two or three child interviews and a similar number of sessions with the parents. Most of this clinical work was done by child psychiatry residents and experienced social workers. Information contained in these written evaluations includes demographic characteristics, presenting complaints and reasons for referral, a thorough developmental history of the child patient, and a marital history of the parents. In addition, descriptions of the child and parent interviews are provided, often with extensive process notes, and a diagnostic formulation with attendant recommendations is presented.

Initially, the completed outpatient evaluations were sorted according to marital history of the parents. Of the 500 evaluations, $161(32.2 \%)$ involved children who had experienced a parental divorce. In an additional 39 cases $(\mathbf{7 . 8 \% )}$ the parents were separated for varying amounts of time. Since it could not be determined how many of these 39 cases 
would eventually result in parental divorce, the children of divorce sample initially was restricted to the 161 youngsters whose parents already had divorced. Due to the small number of children who were under seven years old, this group of 28 cases was excluded from the sample. To increase the number of latency girls in the final sample, $11 \mathrm{di}$ vorce cases evaluated just prior to those in the original sample were added. Thus, our final sample had 144 youngsters.

\section{Coding Procedures}

A coding device was constructed that would permit abstracting and quantifying relevant information from the richly elaborated written evaluations. Variables relevant to this study were sex, race, and current age of the referred child, and age of the youngster at the time of both the parental separation and the divorce. The degree of a child's emotional disturbance was judged using an 11-point scale of emotional disturbance (ED), and the youngster's problems were coded to a presenting complaints checklist (PCCL) comprised of 28 categories. The ED scale, with a range of zero to ten, was constructed as part of this study. The zero point denoted absolutely no evidence of emotional difficulties, points one and two reflected minimal and usually transient problems, points three to five were scored when mild disturbance was clearly present, six and seven were coded when there was clear-cut evidence of emotional disturbance on a moderate level, and points eight to ten were for the moderately severe to severe range of adjustment problems. The upper end was reserved for borderline and psychotic disturbances. The other major instrument, the PCCL, was used in an earlier study of a child guidance population. ${ }^{16}$ Its categories cover problematic behavior and feelings presented by child psychiatric patients. The list of categories will be presented in TABLE 5.

After refining the coding procedures using outpatient evaluations from an earlier time period and therefore not in the current sample, 20 cases, which included boys and girls across the age range in our sample, were selected unsystematically for purposes of establishing reliability. Two clinicians independently reviewed the 20 outpatient evaluations and coded the information in them. Coding for sex, race, and current age yielded perfect intercoder agreement except for one clerical error. There was also very high agreement on coding age of the youngster at the time of parental separation and subsequent divorce $(r=.99$ for both). The ED scale, a clinical judgment based on a reading of the entire written outpatient evaluation, was reliably coded $(r=.92)$. The PCCL was also used reliably, with the median percent agreement for the presentabsent distinction across categories at $93 \%$.

\section{Data Analyses}

The final sample of 144 youngsters was divided into four subgroups by crossing two age levels, latency and adolescence, with sex of the child patients. Latency-age children were those between seven and 11.5 years old at the time of evaluation, while the adolescents ranged from 12 to 17.5 years old (all ages were rounded to the nearest half year). The construction of these four subgroups permitted more straightforward comparisons of our findings with other results reported in 
the literature, and also served to control simultaneously for sex and current age/ developmental level.

For each of the two dependent variables, the ED scale and the PCCL, descriptive information was obtained for the full sample and each of the four subsamples. Then the relationship between timing of the marital dissolution and both the ED scale and PCCL was assessed for the total sample and separately within each of the subsamples.

The timing of the marital dissolution was reflected in coding both the age of the youngsters when their parents separated and when the divorce became final. For several of the analyses, these two variables were each divided into three levels on an a priori basis. The pre-oedipal group consisted of children who were 0 to 2.5 years old when their parents separated/divorced. The oedipal phase group ranged between three and 5.5 years old, and the postoedipal group was at least six years old at parental separation/divorce (again, ages were rounded to the nearest half year). These groups will be alternately referred to as early, ocdipal. and late, respectively. There was often less than one year between the reported parental separation and the divorce. We chose to analyze both age at separation and divorce in order to increase the likelihood of our capturing accurately the timing of the divorce process. rather than for the purpose of making a conceptual distinction between these two events.

The relationship hetween age at parental separation/divorce and ED scores in the total sample and within the four subsamples was assessed in two ways. First, Pearson product-moment correlations were calculated between each of the two timing variables and the ED scale. Negative correlations would support the cumulative deficit hypothesis, while positive correlations would lend weight to the recency position. The critical stage (specifically, oedipal phase) hypothesis was examined by use of one-way analysis of variance, with mean ED scores for the three age periods at separation/divorce compared.

Potential associations between the timing of marital dissolution and the PCCL were analyzed for the full sample by constructing a $2 \times 3$ contingency table for the categories of the PCCL. Presence-absence of each category was compared across the three age levels at parental separation and divorce. Posterior comparisons were carried out whenever the maximum likelihood chisquare for a table reached significance at or beyond .10. Similar contingency tables were used for the within-subgroup analyses, but due to restricted numbers of subjects each $2 \times 3$ table was collapsed into $2 \times 2$ tables comparing the relative incidence of a symptom for each age at separation/divorce (early, oedipal, late) with the other two age levels. Fisher Exact tests were performed for these $2 \times 2$ tables. It is recognized that such tests are partially redundant within any one contingency table, and that the probabilities obtained will yield somewhat inflated levels of statistical significance. Nonetheless, using the Fisher test in this fashion can help begin to lay bare the presence of important trends in the data.

\section{RESULTS}

\section{De'mographic Characteristics}

Before proceeding to the analyses of the data bearing on the relationships between the timing of parental divorce and the effects on children, a description 
Table 1

AGE/SEX TABULATONS FOR THE FINAL SAMPLE

\begin{tabular}{lccc}
\hline \hline & LATENCY $(7-11.5)$ & ADOLESCENCE $(\geqslant 12)$ & TOTAL \\
MALE & $30.6 \%(N=44)$ & $21.5 \%(N=31)$ & $52.1 \%(N=75)$ \\
FEMALE & $22.2 \%(N=32)$ & $25.7 \%(N=37)$ & $47.9 \%(N=69)$ \\
TOTAL & $52.8 \%(N=76)$ & $47.2 \%(N=68)$ & $100.0 \%(N=144)$ \\
\hline
\end{tabular}

of the composition of the sample will provide a context within which results may be interpreted. The sex and current age characteristics of the sample are shown in TABLE 1. After deleting the boys and girls under seven years old and adding 11 latency-age girls who were evaluated during a time period adjacent to the one in which the original sample of 500 was gathered, the proportions of boys and girls were roughly equal, as were the percentages of latency and adolescent children. The racial composition of the sample was predominantly white; only 20 youngsters were non-Caucasian.

In addition to specifying the current age of the children, it is important to understand the relationship between the timing of the parental marital dissolution and the current referral. Two perspectives are helpful in this regard-the age of the child at the marital separation and the time elapsed from separation to referral. Of 139 cases (for five cases this information was missing), 61 (43.9\%) were pre-oedipal at separation, 34 (24.5\%) were oedipal age, and 44 (31.7\%) were postoedipal. With respect to the elapsed time, 16 cases $(11.5 \%)$ were referred within two years or less of the separation, $33(23.7 \%)$ in the span from greater than two years up to five years, and $90(64.7 \%)$ after five years. Thus, many of the children were quite young at the parental separation, and a majority of the sample was referred long after this event.

The economic status of the households in which these children were living is summarized in TABLE 2. The percentages given are based on the 87 cases for which this information was available. Although nearly half of these children came from households that could be characterized as roughly middleclass (gross annual income between $\$ 10,000$ and $\$ 24,999$ ), it is important to note that $40 \%$ of the written evaluations did not contain sufficient information to determine gross yearly income.

Emotional Disturbance Scale Analyses

The means and standard deviations on the ED scale for the total sample and for each of the four subsamples are given in TABLE 3 . The means for the entire sample and the four subgroups fell into the range of moderate disturbance

\section{Table 2}

YEARLY INCOME OF CHILOREN'S HOUSEHOLDS AT THE TIME OF EVALUATION

\begin{tabular}{lcc}
\hline \hline INCOME & $N$ & $\% "$ \\
$\$ 6000$ & 21 & $24.1 \%$ \\
$\$ 6000-\$ 9999$ & 19 & 21.8 \\
$\$ 10,000-\$ 14,999$ & 24 & 27.6 \\
$\$ 15,000-\$ 24,999$ & 17 & 19.5 \\
$\$ 25,000+$ & 6 & 6.9 \\
\hline
\end{tabular}

"Percentages are based on the 87 cases for which this information was available. 
Table 3

EMOTIONAL DISTURBANCE SCALE MEANS AND STANDARD DEVIATIONS

\begin{tabular}{lcc}
\hline \hline GROUP & MEAN & SD \\
Latency boys & 6.59 & 1.35 \\
Latency girls & 6.50 & 1.41 \\
Adolescent boys & 7.00 & 1.74 \\
Adolescent girls & 6.84 & 1.34 \\
Full sample & 6.72 & 1.45 \\
\hline
\end{tabular}

$(6-7)$ on the ED scale. However, scores from one to ten occurred (zero was not coded), with $14.7 \%$ in the absent to mild disturbance interval $(\leqslant 5), 52.4 \%$ at the moderate level $(6-7)$ and $32.9 \%$ moderately seriously to severely disturbed $(8-10)$. A one-way analysis of variance comparing the mean ED scores across the four subgroups was nonsignificant $\left(F_{3.139}=.81\right)$.

In order to investigate the possibility of relationships between children's ED scores and age at marital dissolution, Pearson product-moment correlation coefficients were calculated in two ways. In the left half of TABLE 4, the straightforward correlations for the full sample and the four subsamples are presented, while the right half of the table contains partial correlations with cur- rent age held constant. These partial correlations institute a statistical control for differences on current age in the full sample and within each subsample.

When the usual Pearson correlations were calculated, no significant linear relationships were found, even at a liberalized level of $p<.10$, between age at either separation or divorce and degree of emotional disturbance. The analysis using partial correlations yielded similar results, with the exception of the emergence of two statistically significant findings, one for the adolescent male subsample and one for the full sample. In each case, the child's age at parental divorce was negatively related to level of emotional disturbance. All correlations save one in TABLE 4 are negative, and 18 of 20 account for less than five percent of the variance in ED scores. The abundance of negative correlations in combination with the relatively low strength of association reflected in these tests suggests minimal support for the cumulative deficient hypothesis, in which the earlier the divorce, the greater the child's emotional disturbance. No support for the recency hypothesis was found.

These correlational analyses simulta-

Table 4

CORRELATIONS BETWEEN EMOTIONAL DISTURBANCE SCORES AND TIMING OF THE DIVORCE PROCESS

\begin{tabular}{lccccc}
\hline \hline & \multicolumn{2}{c}{ CORRELATIONS } & & \multicolumn{2}{c}{ PARTIAL CORRELATIONS } \\
\cline { 2 - 3 } GROUP & AGE AT & AGE AT & & AGE AT & AGE AT \\
SEPARATION & DIVORCE & & SEPARATION & DIVORCE \\
Latency boys & -.03 & -.05 & & -.20 & -.23 \\
Latency girls & -.20 & -.18 & & -.20 & -.17 \\
Adolescent boys & +.03 & -.16 & & -.15 & $-.32^{*}$ \\
Adolescent girls & -.08 & -.16 & & -.07 & -.14 \\
Full sample & +.01 & -.09 & & -.09 & $-.18 *$ \\
\hline$p<.10: \cdots p<.05$. & & & & \\
\hline
\end{tabular}


neously address the cumulative deficit and recency hypotheses. To examine the critical stage hypothesis, a nonlinear form of analysis was needed. The possibility that marital dissolution during the child's oedipal phase has especially pronounced effects on emotional growth and adjustment was explored with one-way analyses of variance. Comparisons of the three age groupsearly, oedipal, and late-were conducted for the full sample and the four subsamples, with ED score as the dependent variable. None of these tests approached statistical significance.

Timing of the parental divorce process is essentially unrelated, linearly and nonlinearly, to degree of emotional disturbance in our group. The only hypothesis that received any support at all was the cumulative deficit hypothesis. and the evidence in its favor was minimal. But it is possible that, while timing is not associated for the most part with severity of emotional disturbance, the forms of emotional distress and behavior problems these youngsters developed may be tied to their developmental level at parental separation and divorce.

\section{Presenting Complaints Checklist: Descriptive Analyses}

The types of problems manifested by children in our sample at the time they were evaluated were categorized according to the 28 -item presenting complaints checklist (PCCL). After reviewing a written outpatient evaluation, the coders determined, for each category, whether that difficulty was present or absent for the patient. The percentages of the full sample and of each of the four subsamples having symptoms coded present are shown in TABLE 5 , which indicates several interesting phenomena. The most common presenting complaint was subjective psychological symptoms, a category that included anxiety, sadness, pronounced moodiness, phobias, and depression. In all subgroups, over half the youngsters were suffering from these forms of distress. Academic problems, which included poor grades or grades that were substantially below ability or recent past performance, was the next most frequently observed symptom category, with over half the sample having this difficulty. Aggression toward parents as part of the presenting picture was seen in $43 \%$ of the full sample and was the third most common type of difficulty. This category was coded when physical or verbal aggression toward at least one parent was clearly a feature of the child's difficulties. It is noteworthy that all subgroups evidenced these three most frequently observed problems in substantial proportions, with no significant differences among the groups in their rate of occurrence.

Of the 28 complaints listed in TABLE 5 , 16 occurred so infrequently or with such low expected frequencies in several cells that differences among the four subgroups could not be tested in a $2 \times 4$ contingency table (present-absent $\times 4$ subgroups). Of the 12 that could be tested, nearly half (five) yielded statistically significant group differences beyond the .06 level. An additional five categories had markedly discrepant rates of occurrence among the groups. Drug involvement, alcohol involvement, sexual behavior, running away, and school refusal/truancy were extremely rare to absent in both latency subgroups and most frequent in the adolescent female sample. These striking developmental and sex differences 
Table 5

PROPORTION OF EACH GROUP WITH PCCL PROBLEMS PRESENT

COMPLAINT

1. Aggression toward parents

2. Aggression toward siblings

3. Aggression toward peers

4. Aggression toward inanimate objects

5. Nonaggressive disturbance w/parents

6. Nonaggressive disturbance $w /$ siblings

7. Nonaggressive disturbance $w /$ peers

8. Danger to self

9. Drug involvement

10. Alcohol involvement

11. Sexual behavior

12. Running away

13. School refusal/truancy

14. Academic problems

15. School behavior problems

16. Problems with the law

17. Stealing

18. Medical problems

19. Somatization

20. Enuresis

21. Encopresis

22. Sleep disturbance

23. Eating disturbance

24. Compulsive rituals

25. Subjective psychological symptoms

26. Bizarre behavior

27. Custody dispute

28. Prophylactic concern

LATENCY LATENCY
BOYS
GIRLS

ADOLES- ADOLES-

CENT

BOYS

CENT

GIRLS

FULL SIGNIFI.

SAMPLE CANCE.

\begin{tabular}{|c|c|c|c|c|c|}
\hline $34 \%$ & $41 \%$ & $48 \%$ & $51 \%$ & $43 \%$ & NS \\
\hline 32 & 38 & 45 & 22 & 33 & NS \\
\hline 41 & 25 & 32 & 11 & 28 & .02 \\
\hline 18 & 25 & 29 & 5 & 19 & .04 \\
\hline 23 & 28 & 23 & 16 & 22 & NS \\
\hline 0 & 3 & 3 & 0 & 1 & b' \\
\hline 23 & 28 & 29 & 24 & 26 & NS \\
\hline 5 & 3 & 3 & 14 & 6 & b \\
\hline 0 & 0 & 16 & 35 & 13 & $n$ \\
\hline 0 & 0 & 10 & 22 & 8 & " \\
\hline 2 & 3 & 16 & 32 & 13 & b \\
\hline 2 & 0 & 6 & 22 & 8 & " \\
\hline 2 & 0 & 13 & 19 & 8 & "1" \\
\hline 59 & 47 & 65 & 54 & 56 & NS \\
\hline 59 & 28 & 39 & 16 & 37 & .001 \\
\hline 9 & 0 & 3 & 5 & 5 & ${ }^{n}$ \\
\hline 23 & 6 & 32 & 14 & 19 & .04 \\
\hline 14 & 3 & 13 & 16 & 12 & b \\
\hline 9 & 9 & 7 & 8 & 8 & " \\
\hline 20 & 19 & 13 & 3 & 14 & .06 \\
\hline 5 & 0 & 0 & 3 & 2 & ${ }^{n}$ \\
\hline 21 & 19 & 10 & 19 & 17 & NS \\
\hline 5 & 3 & 7 & 11 & 6 & " \\
\hline 2 & 3 & 0 & 0 & 1 & b \\
\hline 68 & 69 & 55 & 60 & 63 & NS \\
\hline 7 & 6 & 10 & 3 & 6 & 11 \\
\hline 0 & 3 & 0 & 5 & 2 & $"$ \\
\hline 2 & 0 & 0 & 0 & 1 & a \\
\hline
\end{tabular}

aignificance refers to a statistical comparison of the four subgroups in rates of occurrence of the symptom.

"Cannot be tested.

in frequency of problem type for a total of ten of the 28 categories are consistent with earlier findings. 9.21

The findings presented in TABLE 5 can be used to synthesize separate profiles for the four subgroups of patients. To illustrate, the column for latency-age boys indicates that many are evidencing subjective psychological and schoolrelated difficulties. They also are having problems with aggression across a variety of relationships (parents, siblings, and peers), and are experiencing developmental arrests or regressions in toilet training, sleep patterns, and their relationship with at least one parent (i.e.. 
the nonaggressive disturbances with parents category typically reflects an overly entangled, dependent, or libidinized relationship with a parent). Stealing and nonaggressive disturbances with peers are also present for more than a fifth of these boys. By contrast, this sort of profile analysis yields a very different picture for adolescent girls. Aggression within the family, mostly toward parents; academic but not behavior problems in school; and pronounced difficulty in coping with the major issues of impulse control that confront all teenagers are important features of the adolescent girls' profile.

The profiles of presenting problems and the comparisons among the four subgroups in the incidence of each category of the PCCL provide descriptive information. We now turn to analyses of the relationship between timing of the divorce process and the rate of occurrence of types of psychological difficulties.

\section{PCCL and Timing of Parental Divorce Process}

Full sample analysis. For the analysis of the total sample, $2 \times 3$ contingency tables were constructed, with presenceabsence of a complaint crossed with the three age levels (early, oedipal, late) denoting how old the child was at the time of the separation/divorce. When a contingency table was significant at .10 or less, post-hoc comparisons were used to delineate the pattern of the obtained significance.

School refusal/truancy $(p<.01)$ and academic problems $(p<.04)$ were significantly associated with age at parental separation in our total sample. Posterior comparisons revealed that those youngsters who were postoedipal when their parents separated showed a significantly higher incidence of school refusal/truancy than those who experienced parental separation earlier. Parental separation during the child's oedipal years was significantly associated with a greater frequency of academic problems. In addition to these statistically significant findings in regard to age at separation, a relationship between presence of nonaggressive disturbances with parents and preoedipal parental separation was in evidence and approached significance. This association reached statistical significance $(p<.02)$ with respect to age at divorce. School refusal/truancy fell just short of statistical significance and showed a tendency for children experiencing a divorce when they were older to have a high incidence of this difficulty.

The paucity of statistically significant findings in the full sample analysis could represent a masking of important relationships that occur within the four subsamples. Sex and developmental differences in how psychological problems are manifested can "cancel out" when age-sex controls are not used, a point illustrated elsewhere. ${ }^{9}$ With this in mind we turn now to examination of these subsamples separately.

Subsample analyses. Within each subsample, the relationship between age at parental separation/divorce and types of difficulty manifested was assessed. Each resulting $2 \times 3$ table was collapsed in such a way as to compare the incidence of a given complaint at one age level with its relative occurrence at the other two age groups combined. These resulting $2 \times 2$ tables were tested for significance, using the Fisher Exact Test. A summary of these findings is presented in TABLE 6. 


\section{Table 6}

RELATIONSHIP• BETWEEN TIMING OF THE DIVORCE PROCESS AND OCCURRENCE OF PSYCHOLOGICAL PROBLEMS

\begin{tabular}{|c|c|c|c|}
\hline \multirow[b]{2}{*}{ GROUP } & \multicolumn{3}{|c|}{ AGE OF CHILD DURING DIVORCE PROCESS } \\
\hline & EARLY $(0-2.5)$ & OEDIPAL (3-5.5) & LATE (6 and over) \\
\hline Latency boys & $\begin{array}{l}\text { Nonaggression with } \\
\text { parents*** }\end{array}$ & $\begin{array}{l}\text { School behavior } \\
\text { problems* } \\
\text { (Subjective symptoms*) }\end{array}$ & $\begin{array}{l}\text { Nonaggression with } \\
\text { peers* } \\
\text { (Aggression with } \\
\text { objects*) }\end{array}$ \\
\hline Latency girls & $\begin{array}{l}\text { Aggression with } \\
\text { peers } \\
\text { Nonaggression with } \\
\text { parents** }\end{array}$ & & \\
\hline Adolescent boys & $\begin{array}{l}\text { (Nonaggression with } \\
\text { peers"*) } \\
\text { (Academic problems*) }\end{array}$ & $\begin{array}{l}\text { (Aggression with } \\
\text { parents*) } \\
\text { (Aggression with siblings*) }\end{array}$ & School refusal \\
\hline Adolescent girls & & $\begin{array}{l}\text { Aggression with parents"* } \\
\text { Aggression with peers:" } \\
\text { Academic problems**" }\end{array}$ & (Academic problems*) \\
\hline Full sample & $\begin{array}{l}\text { Nonaggression with } \\
\text { parents"* }\end{array}$ & Academic problems"* & $\begin{array}{l}\text { School refusal/ } \\
\text { truancy"* }\end{array}$ \\
\hline
\end{tabular}

- Some of the significance levels indicated here refer to age at separation, others to age at divorce; since age during the divorce process is of interest, separation and final divorce are not distinguished here.

n Problem categories indicated in parentheses denote a lower occurrence of the problem, those presented without parentheses denote a higher incidence.

p. $10 ;$; p .05; **p 01 .

In the latency male group $(N=44)$, both early parental separation $(p<.05)$ and early divorce $(p<.01)$ were significantly associated with a higher incidence of nonaggressive disturbances in the relationship between parents and youngster. A greater occurrence of nonaggressive disturbances with peers and a lower rate of aggression toward inanimate objects were associated with later (postoedipal) separation $(p<.06)$ and divorce $(p<.09)$. For children who were of oedipal age when their parents separated, a higher rate of school behavior problems $(p<.08$ ) and a lower incidence of subjective psychological symptoms $(p<.07)$ was in evidence, indicating a propensity to act on the feelings of distress rather than internalize them.

In the group of latency-age girls, just as among the latency boys, those who were very young (preoedipal) when their parents divorced evidenced a higher rate of occurrence of nonaggressive disturbances with parents $(p<.02)$. For girls who were preoedipal when their parents separated, a similar trend fell just short of significance $(p<.11)$. The only other statistically significant result in this subsample was a relationship between aggressive problems with peers and early parental separation $(p<.04)$.

Turning to the adolescent male group, early parental separation was associated 
with significantly fewer problems of a nonaggressive sort with peers $(p<.03)$ and fewer academic problems $(p<.07)$. A significantly lower occurrence of aggression toward parents and siblings (both $p<.10$ ) was associated with parental separation during the child's oedipal period, while postoedipal separation $(p<.06)$ and divorce $(p<.07)$ were both related to a higher rate of school refusal/truancy.

Adolescent girls who were of oedipal age at parental separation showed a significantly greater incidence of aggression toward parents $(p<.04)$ and of academic problems $(p<.01)$. Both of these findings also occurred for girls whose parents were divorced during the youngster's oedipal period $(p<.02$ and $p<.03$, respectively). Though partially redundant, it is also true that fewer of the girls who were older (postoedipal) when their parents separated/divorced experienced academic problems $(p<.02$ and $p<.01$, respectively). Girls who were in the oedipal phase when their parents divorced also experienced problems of aggression with peers to a significantly greater extent than did girls whose parents divorced at any other time $(p<.05)$. It is interesting to note that adolescent girls, more than either of the two groups of boys, evidenced significant relationships between parental divorce during the oedipal period and specific kinds of problems occurring years later.

Summary of PCCL analyses. The investigation of possible relationships between a youngster's age during the parental divorce process and types of problems seen upon psychiatric referral reveals statistically significant findings for ten categories of the PCCL. It is important to keep in mind that seven categories (Categories 6, 8, 16, 23, 24, 27 , and 28 in TABLE 5) occurred so rarely that significant associations between their presence-absence and the timing of marital dissolution was arithmetically impossible within any of the four subsamples. Thus, nearly half of the categories $(10 / 21)$ that could be tested for at least one subgroup yielded associations with timing of separation/ divorce. That only three of these categories were involved in statistically significant findings for the total sample, and that none of the three were significant in all or even most of the four subsamples, confirms again that failure to control for sex and current age gives rise to misleading results in studies of children's psychological adjustment.

The within-subgroup analyses yielded interesting patterns of relationship between divorce timing and later difficulties. Perhaps most striking was the relationship between parents parting early in the child's life ( $0-2.5$ years old) and a higher incidence of nonaggressive disturbance with the parents. This was true of both latency-age boys and girls. Since all youngsters in these two groups were between seven and 11.5 years old when they were evaluated, this result suggests a long-term effect that is in evidence four to 11 years after the parental separation/divorce.

Another notable result was the differential effects between adolescent boys and girls who experienced parental separation/divorce during their oedipal phase. The adolescent boys showed less aggression towards parents and siblings than did adolescent boys who were younger or older when their parents marriage ended. In contrast, adolescent girls who were of oedipal age when their parents separated/divorced showed 
more aggression toward parents and peers than did adolescent girls who were preoedipal or postoedipal when their parents divorced. A direct comparison involving these aggression categories between the adolescent boys and girls who were 3-5.5 years at parental separation/divorce further accentuated these differences.

\section{DISCUSSION}

The incidence of children of divorce in our original sample of 500 completed outpatient evaluations was nearly identical to the one found in a similar sample at the same clinic. 9 In the current sample, $32.2 \%$ of the youngsters had experienced a parental divorce, and an additional $7.8 \%$ had parents who were separated. The corresponding figures for the earlier sample were $32.6 \%$ and $8.8 \%$, respectively. Similarly, the three most commonly occurring problems for the current sample-subjective psychological problems, academic problems, and aggression toward parents-were also the three most frequently observed difficulties in the earlier sample. And, again, adolescent girls of divorce exhibited markedly high incidences of alcohol and drug involvement, as well as sexual behavior associated with psychiatric referral. Thus, the incidence of children of divorce and the types of problems they evidence at evaluation have been consistent over a three-year period at our outpatient clinic.

The search for possible linear and nonlinear relationships between age of children during the divorce process and subsequent degree of emotional disturbance in the subgroups or in the total sample yielded a dearth of significant findings. The critical stage and recency hypotheses failed to find any support with respect to the extent of distress experienced later by children of divorce. The cumulative deficit view received minimal support. It may be argued that this sample, referred because of concern about their emotional well-being, provides too narrow a perspective. While strong confirmation of a particular hypothesis may have been found in a normative sample, it is worthwhile to note that a wide range of disturbance-adjustment was represented in our sample, including nearly $15 \%$ viewed by the clinician judges as having only mild emotional difficulties. If a systematic relationship between the age of youngsters at parental separation and divorce and subsequent child disturbance-adjustment existed in our data, it had a chance to be revealed. Yet nearly all findings were nonsignificant, and no such clearly systematic association emerged.

This was not the case with respect to the timing of marital dissolution and the kinds of difficulties these children were experiencing. One striking finding was that separation and subsequent divorce during the child's earliest years was associated with a significantly higher incidence of nonaggressive disturbances in the parent-child relationship in both the male and female latency-age groups. It seems that when marital dissolution occurs at a time that youngsters are coping with the normal developmental task of separating from parents, particularly mother, a special vulnerability to separation-related difficulties in latency may be established. Since our data are not longitudinal, it is unclear whether these difficulties were manifest from the time of separation/divorce, or even pos- 
sibly prior to the beginnings of the divorce process, or whether they lay dormant for several years and were then triggered during latency. The move into elementary school and peer expectations for greater independence from parents may reveal a previously quiescent or unnoticed problem constellation.

Turning the focus to marital dissolutions that occurred during the youngsters' oedipal years, several significant findings emerged. Among the adolescent girls, there were higher rates of occurrence of academic problems and of aggression toward both parents and peers, when compared to adolescent girls whose parents' marriages dissolved earlier or later than the oedipal phase. These findings are particularly interesting because so much of the literature has emphasized the effects of father-absence on boys, with little attention paid to potential problems for girls. In contrast, adolescent boys who were of oedipal age at the time of the divorce process showed a significantly lower incidence of aggression toward both parents and siblings. Perhaps boys who experience parental divorce during their oedipal years are prone to inhibiting aggression in the face of adolescent psychosexual changes. Revived fantasies of oedipal victory, accompanied by guilt and anxieties, may pressure more of these youngsters to keep a tighter rein on their aggressive impulses. But for the girls the reverse seems true. They are more openly and problematically hostile than both their male counterparts and other adolescent girls who experienced the divorce process carlier or later than the oedipal phase. The absence of a similar finding among latency-age girls suggests that rage over the divorce, with the attendant psychological loss of the oedipal object (as opposed to the boys" "victory" over the oedipal rival), could lie dormant until adolescence. A "time bomb" effect may occur, in which these girls get on reasonably well with their mothers (the custodial parent in the vast majority of divorces) until sexual and competitive impulses are newly fueled by the changes of puberty.

Latency-aged girls who experienced the parental marital dissolution during the oedipal years were not significantly different from other latency girls, but latency-aged boys had a significantly higher rate of school behavior problems in conjunction with a lower rate of subjective psychological symptoms. This pattern indicates a proclivity for behavioral expression of conflict, rather than internally experienced distress, among these boys, as compared to their peers whose parents divorced before or after the oedipal phase.

The findings are less clear for youngsters who are of school age and usually past the primacy of oedipal issues when their parents separated and divorced. Higher incidences of nonaggressive disturbances with peers for latency boys and of school refusal for adolescent boys appeared side by side with lower rates of occurrence of both aggression toward inanimate objects among latency boys and of academic problems among adolescent girls. We suspect that the six-or-over category for age at parental separation/divorce was too broad. This category encompasses early latency to mid-adolescence, perhaps making the developmental issues too diverse to enable consistent findings to emerge. 


\section{CONCLUSIONS}

Our conclusions can be summarized in three points. First, the incidence of children of divorce in our sample and the most frequently observed kinds of problems they experienced constitute a replication of findings based on a previous study at the same clinic. ${ }^{9}$ Further, the prevalence of subjective psychological problems, academic troubles, and difficulties with intense angry feelings toward parents closely parallels the nature of distress observed by Kelly and Wallerstein among latency-age and adolescent youngsters of divorce. ${ }^{10.22,24}$ These similarities are particularly striking in that Kelly and Wallerstein focused on children amidst the turmoil of parental divorce and again one year later, while for nearly twothirds of our sample the parental separation had occurred over five years earlier. It is as if the pain of parental divorce, and its particular expressions, was still all too poignantly vivid in our child guidance sample.

The second major finding was that no pronounced linear or nonlinear relationship existed between age of the child during the divorce process and the degree of emotional disturbance observed at the later psychiatric evaluation. Of the three hypotheses, only the cumulative deficit view received even minimal support with respect to degree of disturbance. However, it is worth while noting that only about $11 \%$ of our sample experienced the parental divorce within two years of the psychiatric evaluation. This skew in our sample may have made the impact of recency effects more difficult to observe, resulting in less confidence in the test of that hypothesis.

Third, timing of parental separation/ divorce was associated with different kinds of vulnerabilities. To summarize these findings, marital dissolution very early in a child's life, two-and-a-half years or younger, was associated with separation-related difficulties during latency for boys and girls alike. Divorce during the oedipal phase showed the greatest effects in our adolescent groups, with a pronounced sex difference in evidence. Parental divorce in this critical stage seems to be linked to a relative inhibition of aggression in adolescent boys and more direct problematic aggression combined with academic problems for adolescent girls. Among latency boys, a pattern was suggested in which these youngsters act on their conflicts in the school setting rather than being consciously aware of emotional stress. For the group of youngsters whose parents divorced when the child was six or older, the results did not form an integrated picture despite several statistically significant findings. This may have been too diverse a group developmentally to permit a conceptually cohesive set of results to emerge.

The tests of the critical (oedipal) stage and recency hypotheses find no support at all in our data with respect to the degree of emotional disturbance judged during a psychiatric evaluation conducted some time after the divorce. However, there was evidence of a mild cumulative deficit effect. Considerably stronger relationships were found between the timing of parental divorce and the nature of a youngster's difficulties. Despite the often lengthy interval between the divorce and the collection of our data, several statistically significant findings emerged that point toward spe- 
cific patterns. These results are consistent with observations of other children who were amidst a parental divorce, and also seem to reflect conflicts over developmental issues that were ascendant at the time of the divorce process. Our findings suggest that the timing of the divorce, particularly its occurrence during the child's early or oedipal years, may have differential effects on children that can be detected reliably during latency and even as far in the future as adolescence.

\section{REFERENCES}

1. CHETHIX, M. AND KALTER, N. 1980. Developmental arrest following divorce: the role of therapist as developmental facilitator. J. Amer. Acad. Child Psychiat. (in press)

2. DESPERT, J. 1953. Children of Divorce. Doubleday, New York.

3. GARDNER, R. 1976. Psychotherapy with Children of Divorce. Aronson, New York.

4. GARDNER, R. 1977. Children of divorce-some legal and psychological considerations. J. Clin. Child Psychol. 6:3-6.

5. HETHERINGTON, E. 1966. Effects of paternal absence on sex-typed behaviors in Negro and white preadolescent males. J. Pers. Soc. Psychol. 4:87-91.

6. HETHERINGTON, E. 1972. Effects of parental absence on personality development of adolescent daughters. Develpm. Psychol. 7:313326.

7. HETHERINGTON, E., COX, M. AND COX, R. 1976. Divorced fathers. Fam. Coord. 25:417428.

8. hetherington, E., COX, M. AND COX, R. 1978. Play and social interaction in children following divorce. Presented to the NJMH Conference on Divorce, Washington, D.C.

9. KALTER, N. 1977. Children of divorce in an outpatient psychiatric population. Amer. J. Orthopsychiat. 47:40_51.

10. KELLY, J. AND WALlerstein, J, 1976. The effects of parental divorce: experiences of the child in early latency. Amer. Orthopsychiat. 46:20-32.
11. LANDIS, J. 1960 . The trauma of children when parents divorce. Marr. Fam. Living 22:7-13.

12. MC DERMOTT, J. 1968 . Parental divorce in early childhood. Amer. Psychiat. 124:14241432.

13. MC DERMOTT, J. 1970. Divorce and its psychiatric sequelae in children. Arch. Gen. Psychiat. 23:421-427.

14. MORRISON, J. 1974. Parental divorce as a factor in childhood psychiatric illness. Comprehens. Psychiat. 15:95-102.

15. NeUBAUER, P. 1960. The one-parent child and his oedipal development. Psychoanal. Study of the Child 15:286-309.

16. REMBAR, J. 1978. Only children of divorce in an outpatient psychiatric population. Unpublished doctoral dissertation, University of Michigan.

17. SUgAR, M, 1970. Children of divorce. Pediatrics 46:588-595.

18. Tessman, L. 1978. Children of Parting Parents. Aronson, New York.

19. TOOLEY, K. 1976. Antisocial behavior and social alienation post divorce: the "man of the house" and his mother. Amer. J. Orthopsychiat. 46:33-42.

20. TOOMAN, M. 1974. The child of divorce. In Therapeutic Needs of the Family: Problems, Descriptions, and Therapeutic Approaches, H. Hardy and J. Cull, eds. Charles C Thomas, Springfield, Ill.

21. TUCKMAN, J. AND REGAN, R. 1966. Intactness of home and behavioral problems in children. J. Child Psychol. Psychiat. 7:225-233.

22. WALLERSTEIN, J. AND KELLY, J. 1974. The effects of parental divorce: the adolescent experience. In The Child and His Family: Children at Psychiatric Risk, E. Anthony and C. Koupernik, eds. John Wiley, New York.

23. WALLERSTEIN, J. AND KELLY, J. 1975. The effects of parental divorce: experiences of the preschool child. Amer. Acad. Child Psychiat. 14:600-616.

24. WALLERSTEIN, J. AND KELLY, J. 1976. The effects of parental divorce: experiences of the child in later latency. Amer. J. Orthopsychiat. 46:256-269.

25. WESTMAN, J. 1972. Effect of divorce in a child's personality development. Med. Aspects Hum. Sexual. 6:38-55.

26. WESTMAN, J. ET AL. 1970. Role of child psychiatry in divorce. Arch. Gen. Psychiat. $23: 416-420$. 